\title{
Keanekaragaman Flora di Hutan Mangrove Kawasan Pesisir Teluk Mandar, Polewali, Propinsi Sulawesi Selatan: Kajian Pendahuluan
}

\author{
Flora Diversity of Mangrove Forest in the Coastal Zone of Mandar Bay Polewali, South \\ Sulawesi Province: a Preliminary Study
}

\section{Pramudji}

Bidang Sumberdaya Hayati Laut, Pusat Penelitian Oseanografi-LIPI, Jl. Pasir Putih No 1, Ancol Timur, Jakarta.

\begin{abstract}
The sudy of mangrove forest in the coastal zone of Mandar Bay, Polewali, Province of South Sulawesi was carried out from July $21^{\text {st }}$ to July $28^{\text {th }}$ 2002. Data was collected from 5 locations (Panampeang Island, Battuwai Island, Salamah Island, Koremasang Island, and coastal zone of Binnuang) following transect method. The result showed that mangrove in the coastal zone of Mandar Bay was dominated by Rhizophora stylosa and Sonneratia alba. The floristic composition of mangrove forest consist of 29 species. Recently, the extent of mangrove forest in this area was decreasing due to the conversion of mangrove into human settlement, fishpond and uncontrolled mangrove exploitation. This situation lead to the depletion of the living organisms, which are living in this area.
\end{abstract}

Key word: Mangrove forest, Mandar Bay, Polewali, South Sulawesi Province.

Diterima: 7 November, disetujui: 12 Maret 2003

\section{Pendahuluan}

Hutan mangrove didefinisikan sebagai suatu formasi hutan yang keberadaannya selalu dipengaruhi oleh pasang surut (Seanger et al., 1983; Tomlinson, 1986). Hutan mangrove merupakan formasi dari tumbuhan yang spesifik di daerah tropik dan subtropik yang umumnya ditemukan disepanjang kawasan pesisir yang relatif terlindung. Namun demikian tidak semua pantai ditumbuhi mangrove, karena untuk pertumbuhannya memerlukan beberapa persyaratan, antara lain adalah kondisi pantainya agak terlindung dan relatif tenang, landai dan mendapat suplai sedimen dari muara sungai.

Hutan mangrove dikenal juga sebagai ekosistem yang sangat komplek, karena didalamnya terjadi proses hubungan timbal balik antara tumbuhan, hewan dan jasad renik beserta lingkungannya. Menurut Soedarma et al. (1991) proses ini lebih banyak ditentukan oleh kebeadaan air tawar yang tergantung pada frekuensi dan volume pasang-surut, volume masuknya air tawar dan penguapan udara. Perubahan kualitas massa air yang bergerak keluar maupun masuk ke hutan mangrove sangat penting dalam sistem pertukaran hara, karena pada hakekatnya air merupakan media transportasi utama materi dalam lingkungan mangrove. Snedaker (1978) dan Srivastana et al. (1980) mengemukakan bahwa hutan mangrove mampu mengatur keseimbangan lingkungan dan membentuk mata rantai makanan yang sangat berguna bagi kehidupan biota laut. Secara ekologis, hutan mangrove juga mempunyai peranan yang sangat penting, antara lain adalah sebagai pelindung pantai, pencegah intrusi air laut, sebagai tempat mencari makan, tempat pemijahan, tempat asuh dan pembesaran berbagai macam jenis ikan, moluska dan udang. Hutan mangrove juga mempunyai manfaat yang sangat berguna bagi industri, yaitu sebagai penghasil arang yang berkualitas tinggi, disamping sebagai penghasil kayu bakar dan bahan penyamak kulit (Effendi, 1991; Pramudji, 2001a). Selain itu, area hutan mangrove dapat digunakan sebagai lahan 
pertambakan, pertanian, perkebunan dan juga tempat pemukiman serta bangunan dermaga.

Masalah kerusakan hutan mangrove di beberapa daerah di Indonesia saat ini semakin meningkat baik kualitas maupun kuantitasnya, walaupun berbagai macam pertemuan ilmiah banyak dilakukan serta program rehabilitasi digalakkan. Kerusakan hutan mangrove di Indonesia tersebut berkaitan erat dengan faktor meningkatnya populasi manusia, pemenuhan kebutuhan ekonomi baik pada tingkat lokal yakni penduduk sekitar hutan mangrove, maupun pemanfaatan mangrove dalam skala besar oleh para pengusaha tambak, perkebunan dan pertanian (Soemodihardjo, 1983; Soewito, 1984; Pramudji, 2000).

Berkaitan dengan hal tersebut di atas dan untuk mengetahui kondisi hutan mangrove di kawasan pesisir Teluk Mandar, maka dalam artikel ini dibahas hasil penelitian yang dilakukan di kawasan pesisir tersebut. Hasil penelitian ini diharapkan dapat dipakai baik sebagai referensi ilmiah, maupun sebagai rujukan bagi Pemerintah Daerah dalam mengambil kebijaksanaan pengelolaan, pembangunan dan pengembangan wilayah pesisir.

\section{Metode Penelitian}

Penelitian hutan mangrove dilakukan dipesisir dan pulau-pulau dikawasan Teluk Mandar, Kabupaten Polewali, Propinsi Sulawesi Selatan dilakukan pada tanggal 21 Juli sampai dengan tanggal 28 Juli 2002. Penelitian tersebut meliputi kawasan pesisir Pulau Panampeang, Pulau Battuwai, Pulau Salamah, Pulau Koremasang dan pesisir Binnuang.

Pengambilan data vegetasi dilakukan dengan cara menggunakan metode kuadran (Oosting,1956), yaitu dengan cara membuat petak-petak dengan ukuran 10 meter x 10 meter kontinyu di sepanjang garis transek yang dibuat tegak lurus dengan garis pantai. Metode ini juga bertujuan untuk mengetahui jenis tumbuhan mangrove dan pola permintakatannya (zonasi). Dari petak-petak tersebut, kemudian dicatat data vegetasi mangrove yang meliputi jenis tumbuhan mangrove yang hadir, kerapatan tegakan, nilai penting dan basal area jenis. Data vegetasi kemudian dianalisa menggunakan formula yang dikembangkan oleh Cox (1967), Snedaker \& Snedaker (1984) dan English et al., (1994). Di samping data vegetasi hutan mangrove, kondisi lingkungan dan pertambakan yang berkaitan dengan keberadaan hutan mangrove juga dicatat.

\section{Hasil dan Pembahasan}

Dari hasil inventarisasi yang dilakukan pada hutan mangrove di beberapa lokasi pesisir di Teluk Mandar ditemukan sebanyak 28 jenis tumbuhan yang terdiri atas 19 jenis tumbuhan penyusun utama hutan mangrove, sedangkan sembilan jenis lainnya merupakan tumbuhan yang biasa tumbuh berasosiasi dengan mangrove (Tabel 1). Dari sembilan jenis tumbuhan yang berasosiasi dengan hutan mangrove tersebut lima jenis diantaranya termasuk dalam formasi pescaprae (Cyperus maritima, Sesuvium portulacastrum, Ipomea pes-caprae, Pandanus tectorius dan Ischaemum muticum), sedangkan empat jenis lainnya adalah termasuk dalam formasi baringtonia (Baringtonia asiatica, Terminalia catappa, Thespesia populnea dan Hibiscus tiliaceus). Dari seluruh jenis tumbuhan mangrove yang hadir di kawasan ini, Rhizophora stylosa dan Sonneratia alba merupakan jenis yang dominan dan memiliki sebaran yang relatif merata. Hal ini karena kedua jenis tumbuhan mangrove tersebut termasuk jenis pioner yang memiliki daya adaptasi yang cukup tinggi terhadap berbagai kondisi lingkungan pesisir yang sangat ekstrim.

Ditinjau dari aspek keragaman jenisnya, tumbuhan mangrove yang diperoleh di daerah pesisir Teluk Mandar dan beberapa pulau disekitarnya adalah cukup tinggi. Keragaman jenis tumbuhan mangrove di daerah ini paling banyak apabila dibandingkan dengan yang ditemukan di Morowali, Sulawesi Tengah hanya sekitar 11 jenis (Darnaedi \& Budiman, 1984), di pesisir Teluk Kotania, Seram Barat dijumpai 24 jenis (Pramudji, 2001b), di beberapa daerah pesisir Sulawesi Utara ditemukan 20 jenis (Pramudji, 2002), serta di 
daerah pesisir Grajagan, Banyuwangi diperoleh 14 jenis (Soeroyo \& Sukardjo, 1990). Namun demikian, keragaman jenis mangrove di daerah pesisir Teluk Mandar ini lebih rendah bila dibandingkan dengan hutan mangrove di Segara Anakan, Cilacap yaitu tercatat sebesar 75 jenis (Soemodihardjo $d k k, 1991$ ), di pesisir Kepulauan Karimun, Selat Malaka tercatat 31 jenis (Pramudji \& Suroyo, 2001) dan di seluruh pesisir Sulawesi Selatan menurut Nurkin (1994) ditemukan 30 jenis.

Dari hasil pengamatan yang dilakukan nampak bahwa hutan mangrove di daerah ini juga memperlihatkan adanya permintakatan (zonasi), namun terlihat ada perbedaan pola permintakatan antara hutan mangrove di pesisir pulau Panampeang dengan hutan mangrove lokasi lain. Perbedaan pola permintakatan ini kemungkinan disebabkan karena lokasi Pulau Panampeang terletak di daerah teluk paling luar, sehingga hanya jenis Sonneratia alba saja yang mampu tumbuh pada kondisi lingkungan dengan pukulan ombak yang relatif besar.

Kondisi hutan mangrove di kawasan pesisir Teluk Mandar pada umumnya cukup memperihatinkan, kecuali hutan mangrove di pulau Panampeang. Pada umumnya ketebalan hutan mangrove di kawasan ini hanya berkisar antara 15 hingga 200 meter dari garis pantai, hal ini disebabkan karena sebagian besar telah dikonversi menjadi pertambakan dan pemukiman penduduk maupun bangunan dermaga. Dari sejumlah pertambakan yang ada di area hutan mangrove, beberapa lokasi nampaknya sudah diterlantarkan dan ditinggalkan. Oleh karena itu, pemerintah setempat diharapkan ikut memberikan dorongan pada masyarakat agar pertambakan tersebut segera direhabilitasi kembali, karena pada umumnya hutan mangrove di kawasan pesisir pulau-pulau kecil sangat rentan dan sensitif terhadap perubahan lingkungan. Menurut Kusmana (komunikasi pribadi) pulau yang luasnya kurang dari 10 hektar, keberadaannya akan tergantung hutan mangrove, sehingga jika hutan mangrove ditebang habis, kemungkinan terkena erosi sangat tinggi. Selain itu, hutan mangrove di kawasan daratan Polewali perlu dibuat "green belt”, dengan tujuan sebagai stabilisator untuk menghindari kerusakan pantai, serta memperta- hankan peran dan fungsi ekosistem mangrove terhadap lingkungan perairan di sekitarnya.

Dari hasil analisa vegetasi hutan mangrove yang dilakukan di beberapa pulau dan daerah di kawasan pesisir Teluk Mandar, maka untuk masing-masing daerah secara rinci dibahas sebagai berikut:

\section{Hutan mangrove di pulau Koremasang}

Pulau Koremasang merupakan pulau kecil yang tidak berpenghuni dan terletak di kawasan perairan Teluk Mandar paling selatan. Hutan mangrove di kawasan ini dijumpai tumbuh di sepanjang bagian pesisir yang relatif terlindung, dan diperkirakan memiliki ketebalan antara 20 hingga 200 meter. Sebagian besar hutan mangrove di daerah ini kondisinya sudah rusak, hal ini karena hampir di sepanjang area hutan mangrove sudah dikonversi menjadi pertambakan. Dari sejumlah pertambakan yang ada di kawasan ini nampak ada yang sudah tidak dimanfaatkan lagi dan ditumbuhi anakan mangrove (jenis Rhizophora stylosa), oleh karena itu disarankan agar lahan pertambakan yang sudah ditinggalkan tersebut seyogyanya diupayakan untuk direhabilitasi, sehingga diharapkan fungsi dan peran ekosistem tersebut dapat pulih kembali.

Hasil analisa vegetasi jenis tumbuhan mangrove memperlihatkan, bahwa jenis yang dominan di daerah ini adalah Rhizophora stylosa yaitu tercatat memiliki kerapatan sebesar 1420 pohon/ha, dengan nilai penting sebesar $202,19 \%$ dan basal area tercatat 15,30 $\mathrm{m}^{2} /$ ha. Secara keseluruhan, kerapatan tumbuhan mangrove di daerah ini adalah sebesar 1700 pohon/ha, dengan basal area sekitar 18,93 $\mathrm{m}^{2} /$ ha, dan untuk masing-masing jenis ditampilkan pada Tabel 2, 3, dan 4.

Peremajaan dari jenis Rhizophora stylosa banyak ditemukan sekitar garis pantai yang tumbuh berasosiasi dengan seagrass. Selain itu, di bagian belakang juga banyak ditemukan anakan Bruguiera gymnorrhiza dan Rhizophora stylosa. 
2. Hutan mangrove di pesisir Binnuang

Pesisir Binnuang terletak di daratan Sulawesi yang terletak pada daerah teluk yang relatif terlindung dari hempasan gelombang. Di sepanjang kawasan pesisir daerah ini ditumbuhi mangrove yang relatif tinggi dan padat dari jenis Avicennia marina dan Rhizophora stylosa. Mangrove di daerah ini tumbuh di atas substrat lumpur liat, karena kawasan ini sangat dipengaruhi oleh muara sungai. Hutan mangrove di kawasan ini juga sudah dikonversi menjadi pertambakan, namun ada beberapa areal yang terbengkalai dan ditinggalkan nelayan.

Hutan mangrove di daerah ini memiliki kerapatan sebesar 2166 pohon/ha, dengan basal areal tercatat sekitar $23,65 \mathrm{~m}^{2} / \mathrm{ha}$. Sedangkan jenis yang dominan adalah Rhizophora stylosa dengan kerapatan sebesar 1533 pohon/ha, nilai penting tercatat $168,28 \%$ dan basal area 14,94 $\mathrm{m}^{2} /$ ha. Peremajaan alami dari jenis Rhizophora stylosa dan Avicennia marina tumbuh secara sporadis di depan garis pantai terlihat cukup rapat, bahkan di daerah ini juga sudah ada kegiatan penanaman mangrove dari jenis yang sama.

\section{Hutan mangrove di pulau Panampeang}

Pulau Panampeang adalah pulau kecil yang merupakan pulau karang yang terletak paling luar di perairan Teluk Mandar yang ditumbuhi mangrove dan memiliki pantai yang relatif landai. Hutan mangrove di kawasan ini merupakan satu-satunya kawasan yang masih baik kondisinya, karena belum ada kegiatan pertambakan maupun kegiatan lain yang merusak hutan mangrove. Oleh karena itu, kondisi ini diharapkan tetap dipertahankan agar eksistensi dan fungsi ekosistem mangrove dapat berkelanjutan.

Permintakatan atau zonasi jenis tumbuhan mangrove di kawasan ini nampak berbeda dengan daerah lain. Pola permintakatan tersebut dari garis pantai adalah sebagai berikut: tegakkan murni Sonneratia alba hingga sekitar 50 meter, zona dibelakangnya adalah tegakkan campuran Sonneratia albaBruguiera gymnorrhiza yang ketebalannya sekitar 30 meter, kemudian disusul oleh tegakkan campuran Rhizophora stylosaBruguiera gymnorrhiza dan Sonneratia alba dan zona yang terakhir adalah tegakkan campuran Thespesia populnea - Bruguiera gymnorrhiza yang tumbuh dan menempati substrat pasir pecahan karang yang mengering dengan ketebalan sekitar 45 meter.

Dari hasil analisa vegetasi memberikan gambaran bahwa secara keseluruhan kerapatan hutan mangrove di daerah ini adalah sebesar 1063 batang/ha, dengan total nilai basal area adalah sebesar 26,62 $\mathrm{m}^{2} / \mathrm{ha}$ (Tabel 2). Di kawasan ini Sonneratia alba berperan sebagai jenis yang dominan yang memiliki kerapatan sekitar 825 pohon/ha, dengan nilai penting sebesar 231,58 \% serta basal area mencapai $26,62 \mathrm{~m}^{2} / \mathrm{ha}$.

Peremajaan alami yang ada di sekitar garis pantai yang berhadapan dengan laut lepas adalah dari anakan Sonneratia alba, sedangkan yang berhadapan dengan pulau Battuwai adalah dari jenis Rhizophora stylosa. Perkembangan luas area hutan mangrove nampaknya akan terjadi pada kawasan perairan selat antara pulau Pananpeang dengan pulau Battuwai, hal ini karena terlihat kecambah dari jenis Rhizophora stylosa yang banyak tumbuh secara sporadis di sekitar garis pantai dan bahkan terlihat pulau-pulau kecil yang merupakan bentukan dari rumpun Rhizophora stylosa. Fenomena yang terjadi di daerah ini juga pernah ditemukan pada kawasan pesisir daerah Teluk Kotania (Pramudji, 2001b) dan di daerah kepulauan Natuna (Pramudji, 2002).

\section{Hutan mangrove di pulau Battuwai}

Pulau Battuwai merupakan salah satu pulau yang paling luas arealnya di kawasan Teluk Mandar. Di pulau ini sudah banyak bangunan rumah permanen dan bahkan bangunan sekolah. Di antara pulau-pulau yang ada di kawasan Teluk Mandar, pulau Battuwai merupakan pulau yang memiliki hutan mangrove yang paling luas, namun kondisinya juga seperti pulau lainnya, karena di beberapa lokasi sudah dibangun pertambakan. Hal yang sangat positip di kawasan ini adalah sudah terlihat ada upaya penghijauan di beberapa lokasi dengan jenis Rhizophora stylosa. 
Secara keseluruhan, kerapatan hutan mangrove di daerah ini tercatat sebesar 1129 pohon/ha, dengan basal area sekitar 26,55 $\mathrm{m}^{2}$ ha $^{-1}$. Seperti halnya tempat sebelumnya, hutan mangrove di kawasan ini juga didominasi oleh Rhizophora stylosa $(\mathrm{K}=616$ pohon/ha, $\left.\mathrm{NP}=118,57 \% ; \mathrm{BA}=11,75 \mathrm{~m}^{2} / \mathrm{ha}\right)$, terutama di daerah garis pantai hingga 40 meter, sedangkan jenis kodominannya adalah Sonneratia alba $(\mathrm{K}=300$ pohon $/ \mathrm{ha}$; $\left.\mathrm{NP}=102,94 \% ; \mathrm{BA}=12,40 \mathrm{~m}^{2} / \mathrm{ha}\right)$, namun jenis ini cenderung dominan di daerah perbatasan dengan hutan darat dan umumnya berasosiasi dengan Bruguiera gymnorrhiza dan Avicennia marina. Anakan dari jenis Rhizophora stylosa tumbuh secara sporadis di antara seagrass di kawasan selat antara pulau Panampenang dan pulau Battuwai, sedangkan dalam hutan mangrove banyak dijumpai anakan Sonneratia alba, Bruguiera gymnorrhiza dan juga jenis Rhizophora stylosa.

5. Hutan mangrove di pulau Salamah (pulau Tengah)

Pulau Salamah atau pulau Tengah lokasinya berdekatan dengan pulau Battuwai, dan luas areanya lebih kecil dari Pulau Battuwai. Hutan mangrove di daerah ini tumbuh di sepanjang kawasan pesisir, karena posisinya sangat terlindung oleh pulau Battuwai. Jenis tumbuhan Rhizophora stylosa terlihat tumbuh sangat rapat di daerah garis pantai, dan jenis ini penyebarannya hingga perbatasan hutan darat.

Kerapatan hutan mangrove di daerah ini mencapai sebesar 1482 pohon/ha, dan memiliki basal area tercatat sebesar $27,97 \mathrm{~m}^{2} / \mathrm{ha}$. Jenis tumbuhan mangrove yang tercatat memiliki kerapatan tertinggi adalah Rhizophora stylosa $(\mathrm{K}=783$ pohon/ha; $\mathrm{NP}=129,47$ \%; $\mathrm{BA}=13,19$ $\mathrm{m}^{2} / \mathrm{ha}$ ) dan disusul oleh jenis Sonneratia alba $\left(\mathrm{K}=400\right.$ pohon $\mathrm{ha}^{-1} ; \quad \mathrm{NP}=100,32 \%$; $\left.\mathrm{BA}=11,21 \mathrm{~m}^{2} \mathrm{ha}^{-1}\right) . \quad$ Kondisi peremajaan alami di daerah ini juga terlihat tumbuh di sekitar garis pantai, seperti halnya beberapa pulau lainnya.

\section{Kesimpulan}

1. Sebagian besar hutan mangrove di daerah ini sudah dikonversi menjadi pertambakan dan bangunan pemukiman, kecuali di Pulau Panampeang.

2. Suatu fenomena perluasan area hutan mangrove akan terjadi antara pulau panampeang dan pulau Battuwai. Di beberapa lokasi di kawasan ini sudah ada upaya penghijauan yang dilakukan, namun hasilnya belum optimal.

3. Untuk mengembalikan fungsi hutan mangrove secara alami, maka perlu diupayakan penghijauan terutama di daerah pulau-pulau kecil.

\section{Daftar Pustaka}

Cox, G. W. 1967. Laboratory manual of general ecology. M. W. C. Brown Company, Miniepolis 165 pp.

Darnaedi, D. dan A. Budiman 1984. Analisis vegetasi hutan mangrove Morowali, Sulawesi Tengah. Pros. Sem. II Ekos. Hut. Mangrove MAB-LIPI (Soeriangera, I. $d k k$. Eds.): 162-171.

Effendy, R. 1991. Suatu pemikiran pemeliharaan permudaan alam hutan mangrove untuk meningkatkan mutu areal bekas tebangan. Pros. Sem. IV Ekos. Hut. Mangrove MAB-LIPI (Soemodiharjo, S. $d k k$. Eds.): 111-115.

English, S., C. Wilkinson \& V. Baker 1994. Survey manual for tropical marine resources. ASEAN Australia Marine Science Project: Living Coastal Resources. 119-194.

Nurkin, B. 1994. Degradation of mangrove forests in South Sulawesi Imdonesia. Hydrobiologia 285(1-3): 271-240.

Oosting, H. J. 1956. The study of plant communities. W. H. Freeman and Co San Francisco. 356 pp. 
Pramudji 2000. Negative impacts of human activities on mangrove ecosystem in Indonesia. Proc. of the $11^{\text {th }}$ JSPS Seminar on Marine Science. Center for International Cooperation, Ocean Research Institute, University of Tokyo. Minamidai, Nakano, Tokyo. 297-305.

Pramudji 2001a. The Dynamic of mangrove forest area in the coastal zone of Kotania Bay, West Ceram. Oseana XXVI (3): 916.

Pramudji 2001b. Biological resources in the coastal zone of Kotania Bay, West Ceram, Province of Maluku. Pesisir dan Pantai Indonesia. Puslitbang Oseanologi LIPI, Jakarta. Vol 6 (1): 145-152.

Pramudji 2002a. Analisa vegetasi hutan mangrove di beberapa kawasan pesisir Sulawesi Utara. Peisir dan Pantai Indonesian. Puslit Oseanogragi LIPI, Jakarta.

Pramudji dan Suroyo 2001. Laporan kajian hutan mangrove di kawasan pesisir Kepulauan Karimun, Selat Malaka. Tidak dipublish.

Seanger, P., E. J. Hergerl \& J. D. S. Davie 1983. Global status of mangrove ecosystems. By the working group on mangrove ecosystems on the IUCN Commission on Ecology. The environmentalist Vol. 3. Suplement. 88 pp.

Snedaker, S. C. 1978. Mangrove, their values and perpetuation. Nat. Research. 14: 613.

Snedaker, S. C. \& J. G. Snedaker 1984. The mangrove ecosystem: Research methods. Published by the United Nations Educational, Scientific and Cultural Organization. Bungay, United Kingdom. $351 \mathrm{pp}$.
Soedarma, D., S. Hadi \& B. Widyarto 1991. Pola dinamika massa air dan kaitannya dengan pengelolaan mangrove di Teluk Lampung. Pros. Sem. IV Ekos. Hut. Mangrove MAB-LIPI (Soemodihardjo, S. $d k k$. Eds.): 93-100.

Soemodihardjo, S. 1983. The impact of transmigration on the mangrove ecosystem. Paper presented in the workshop on productivity of the Mangrove Ecosystem, Management Implication, Penang, Malaysia. October 1983.

Soemodihardjo, S., Surojo and Suyarso. 1991. The mangrove of Segara Anakan : An assesment of their condition and prospect. In: Toward an integrated management of resources. ICLARM Conference Proceeding. National University of Singapore. 213-222.

Soeroyo dan S. Sukardjo. 1990. Struktur dan komposisi hutan mangrove di Grajagan, Banyuwangi. Pros. Sem. IV Ekos. Hut. Mangrove MAB-LIPI. (S. Soemodihardjo $d k k$. Eds.): 129-136.

Soewito 1984. Status ekosistem hutan mangrove dalam kaitannya dengan kepentingan perikanan di Indonesia dan kemungkinan pengembangannya. Pros. Sem. II Ekos. Hut. Mangrove. MAB-LIPI (Soerianegara I. $d k k$. Eds.): 124-132.

Srivastana, P. B. L., A. Sani \& D. Kamis. 1980. Status and dispersal of natural regeneration in Matang mangrove reserve on Paninsular, Malaysia. Tropical Ecology and Development. 113-120.

Tomlinson, P. B. 1986. The botany of mangroves. Cambridge University Press, Cambridge, London, N.York, N. Rochelle, Melbourne, Sydney. pp. 413. 
Tabel 1. Jenis tumbuhan mangrove dan tumbuhan yang berasosiasi dengan mangrove (*) yang ditemukan di kawasan Teluk Mandar, Polewali, Sulawesi Selatan.

\begin{tabular}{clll}
\hline No & \multicolumn{1}{c}{ Famili } & \multicolumn{1}{c}{ Jenis tumbuhan } & \multicolumn{1}{c}{ Nama daerah } \\
\hline \hline 1 & Rhizophoraceae & Rhizophora apiculata & Bako, lanro, bako tandok \\
& & Rhizophora mucronata & Bako hitam \\
& & Rhizophora stylosa & Bako korap \\
& & Bruguiera gymnorrhiza & Kaja-kajang \\
& & Ceriops tagal & Tangere, tengar \\
2 & Sonneratiaceae & Sonneratia alba & Beroppa, pedada \\
3 & Avicenniaceae & Avicennia marina & Lesse-lesse, api-api putih \\
4 & Myrcinaceae & Aegiceras corniculatum & Utti-utti, teruntun \\
5 & Arecaceae & Nypa fruticans & Nipa, lipa \\
6 & Euphorbiaceae & Excoecaria agalocha & Buta-buta, madengan \\
7 & Sterculiaceae & Heritiera littoralis & Talungan, dungun \\
8 & Combretaceae & Lumnitzera littorea & Bunga-bunga, teruntum \\
9 & Rubiaceae & Schypiphora hydrophyllacea & Giling-kiling, cingam \\
10 & Meliaceae & Xylocarpus granatum & Buli cela, niri, kira-kira \\
11 & Acanthaceae & Acanthus ilicifolius & Elli-elli, jeruju hitam \\
& & Acanthus ebracteatus & Jeruju putih \\
12 & Pteridaceae & Acrostichum aureum & Lappio, paku laut \\
13 & Malvaceae & Hibiscus tiliaceus $*$ & Waru \\
& & Thespesia populnea $*$ & Waru laut \\
14 & Combretaceae & Terminalia cattapa $*$ & Ketapang, beowa \\
15 & Lecythidaceae & Baringtonia asiatica $*$ & Butong, alakkang \\
16 & Leguminaceae & Deris trifoliata & Binre-binreng, tuba laut \\
17 & Bignoniaceae & Dolichandrone spacthacea & Tui, kayu kuda \\
18 & Molluginaceae & Sesuvium portulacastrum $*$ & Gelang, krokot \\
19 & Cyperaceae & Cyperus maritima $*$ & Teki laut \\
20 & Graminae & Ischaemum muticum $*$ & Rumput tembaga \\
21 & Convolvulaceae & Ipomea pes-caprae $*$ & Batata pantai \\
22 & Pandanaceae & Pandanus tectorius $*$ & Pandan \\
\hline & & &
\end{tabular}

Tabel 2. Kerapatan jenis (K=pohon ha $\left.{ }^{-1}\right)$ di Pulau Koremasang (1), daerah Binuang (2), P. Panampeang (3), P. Battuwai (4) dan P. Salamah (5).

\begin{tabular}{lrrrrr}
\hline \multicolumn{1}{c}{ Jenis } & $\mathbf{1}$ & $\mathbf{2}$ & $\mathbf{3}$ & $\mathbf{4}$ & $\mathbf{5}$ \\
\hline \hline Avicennia marina & 100 & 350 & - & 88 & 16 \\
Bruguiera gymnorrhiza & - & - & 125 & 125 & 283 \\
Rhizophora stylosa & 1420 & 1533 & 113 & 616 & 783 \\
Sonneratia alba & 180 & 283 & 825 & 300 & 400 \\
\hline \multicolumn{1}{c}{ Jumlah } & $\mathbf{1 7 0 0}$ & $\mathbf{2 1 6 6}$ & $\mathbf{1 0 6 3}$ & $\mathbf{1 1 2 9}$ & $\mathbf{1 4 8 2}$ \\
\hline
\end{tabular}


Tabel 3. Nilai penting jenis (NP=\%) di Pulau Koremasang (1), daerah Binuang (2), P. Panampeang (3), P. Battuwai (4) dan P. Salamah (5).

\begin{tabular}{lcrrrr}
\hline \multicolumn{1}{c}{ Jenis tumbuan } & $\mathbf{1}$ & $\mathbf{2}$ & $\mathbf{3}$ & $\mathbf{4}$ & \multicolumn{1}{c}{$\mathbf{5}$} \\
\hline \hline Avicennia marina & 31,84 & 76,81 & - & 31,84 & 7,64 \\
Bruguiera gymnorrhiza & - & - & 35,80 & 46,56 & 62,55 \\
Rhizophora stylosa & 202,19 & 168,28 & 32,62 & 118,57 & 129,47 \\
Sonneratia alba & 65,97 & 54,90 & 231,58 & 102,94 & 100,32 \\
\hline \multicolumn{1}{c}{ Jumlah } & $\mathbf{2 9 9 , 6 4}$ & $\mathbf{2 9 9 , 9 9}$ & $\mathbf{3 0 0 , 0 0}$ & $\mathbf{2 9 9 , 9 1}$ & $\mathbf{2 9 9 , 9 8}$ \\
\hline
\end{tabular}

Tabel 4. Basal area jenis $\left(B A=m^{2} h a^{-1}\right)$ di P. Koremasang (1), Binuang (2), P. Panampeang (3), P. Battuwai (4) dan P. Salamah (5).

\begin{tabular}{lrrrrr}
\hline \multicolumn{1}{c}{ Jenis tumbuhan } & \multicolumn{1}{c}{$\mathbf{1}$} & \multicolumn{2}{c}{$\mathbf{2}$} & \multicolumn{1}{c}{} & \multicolumn{1}{c}{$\mathbf{5}$} \\
\hline \hline Avicennia marina & 0,18 & 6,80 & - & 0,78 & 0,13 \\
Bruguiera gymnorrhiza & - & - & 0,8 & 1,62 & 3,04 \\
Rhizophora stylosa & 15,30 & 14,94 & 0,48 & 11,75 & 13,19 \\
Sonneartia alba & 3,45 & 1,91 & 25,34 & 12,40 & 11,21 \\
\hline \multicolumn{1}{c}{ Jumlah } & $\mathbf{1 8 , 9 3}$ & $\mathbf{2 3 , 6 5}$ & $\mathbf{2 6 , 6 2}$ & $\mathbf{2 6 , 5 5}$ & $\mathbf{2 7 , 5 7}$ \\
\hline
\end{tabular}

